OPEN ACCESS

Edited by:

Gayle Kaufman,

Davidson College, USA

Reviewed by:

Eunice Lumsden,

University of Northampton, UK

Lorraine Gray,

University of Northampton, UK

*Correspondence: Isabell Schuster isschust@uni-potsdam.de

Specialty section:

This article was submitted to Gender, Sex and Sexuality Studies, a section of the journal

Frontiers in Psychology

Received: 01 June 2016

Accepted: 24 August 2016

Published: 21 September 2016

Citation:

Schuster I, Krahé B, llabaca Baeza P and Muñoz-Reyes JA (2016) Sexual

Aggression Victimization and Perpetration among Male and Female

College Students in Chile.

Front. Psychol. 7:1354.

doi: 10.3389/fpsyg.2016.01354

\section{Sexual Aggression Victimization and Perpetration among Male and Female College Students in Chile}

\author{
Isabell Schuster ${ }^{*}$, Barbara Krahé ${ }^{1}$, Paola llabaca Baeza ${ }^{2}$ and José A. Muñoz-Reyes ${ }^{3}$ \\ ${ }^{1}$ Department of Psychology, University of Potsdam, Potsdam, Germany, ${ }^{2}$ Escuela de Psicología - Centro Cielo, Universidad \\ Santo Tomás, Santiago, Chile, ${ }^{3}$ Centro de Estudios Avanzados, Universidad de Playa Ancha, Valparaíso, Chile
}

Evidence on the prevalence of sexual aggression among college students is primarily based on studies from Western countries. In Chile, a South American country strongly influenced by the Catholic Church, little research on sexual aggression among college students is available. Therefore, the purpose of the present study was to examine the prevalence of sexual aggression victimization and perpetration since the age of 14 (the legal age of consent) in a sample of male and female students aged between 18 and 29 years from five Chilean universities $(N=1135)$, to consider possible gender differences, and to study the extent to which alcohol was involved in the reported incidents of perpetration and victimization. Sexual aggression victimization and perpetration was measured with a Chilean Spanish version of the Sexual Aggression and Victimization Scale (SAV-S), which includes three coercive strategies (use or threat of physical force, exploitation of an incapacitated state, and verbal pressure), three victim-perpetrator constellations (current or former partners, friends/acquaintances, and strangers), and four sexual acts (sexual touch, attempted sexual intercourse, completed sexual intercourse, and other sexual acts, such as oral sex). Overall, 51.9\% of women and $48.0 \%$ of men reported at least one incident of sexual victimization, and $26.8 \%$ of men and $16.5 \%$ of women reported at least one incident of sexual aggression perpetration since the age of 14 . For victimization, only few gender differences were found, but significantly more men than women reported sexual aggression perpetration. A large proportion of perpetrators also reported victimization experiences. Regarding victim-perpetrator relationship, sexual aggression victimization and perpetration were more common between persons who knew each other than between strangers. Alcohol use by the perpetrator, victim, or both was involved in many incidents of sexual aggression victimization and perpetration, particularly among strangers. The present data are the first to provide a systematic and detailed picture of sexual aggression among college students in Chile, including victimization and perpetration reports by both men and women and confirming the critical role of alcohol established in past research from Western countries.

Keywords: sexual aggression, victimization, perpetration, prevalence, coercive strategies, relationship constellations, alcohol, Chile 


\section{INTRODUCTION}

Being forced to engage in unwanted sexual activities is a serious violation of the right to sexual self-determination. It is a major problem worldwide (WHO, 2013), associated with a wide range of negative effects on survivors' wellbeing (Martin et al., 2011; Choudhary et al., 2012). Studies demonstrating the high prevalence of sexual aggression as reported by victims and perpetrators have been conducted primarily in Western countries (Fisher et al., 2010; Krahé et al., 2014, for reviews). By comparison, little research is available on the problem of sexual aggression in developing countries. In Chile, one of the South American countries with the highest human development index (United Nations Development Programme, 2015), research on sexual aggression victimization and perpetration is notably limited. To address this gap, the primary purpose of the present study was to investigate the prevalence of experiencing and engaging in sexual aggression in a sample of female and male college students in Chile. Additionally, the present study examined the role of alcohol in sexual aggression victimization and perpetration. We defined sexual aggression as behavior carried out with the intent or result of making another person engage in sexual activity despite his or her unwillingness to do so (Krahé et al., 2015), considering different coercive strategies, victim-perpetrator relationship constellations, and sexual acts.

Since Koss et al.'s (1987) groundbreaking research on sexual aggression among college students in the 1980s, many largescale studies, primarily from the United States, revealed high prevalence rates of sexual aggression. For instance, in the Campus Climate Survey on Sexual Assault and Sexual Misconduct that included 27 higher education institutions in the United States, $18.1 \%$ of female students and $4.2 \%$ of male students reported the experience of completed penetration or sexual touch through the use of physical force or incapacitation since entering college (Cantor et al., 2015). In line with this finding, a large body of research has shown higher victimization rates for women than for men (e.g., Black et al., 2011; Williams et al., 2014). At the same time, evidence is accumulating that men also experience sexual victimization to a substantial degree (e.g., French et al., 2015; Krahé et al., 2015).

Fewer studies have studied the prevalence of reported perpetration of sexually aggressive behavior, especially in community or college student samples. Recent studies from the U.S. found that about $30 \%$ of male college students reported some form of sexually aggressive behavior since adolescence (Swartout et al., 2015; Dardis et al., 2016). In a recent German study, the overall prevalence of male perpetration was lower, but still substantial with 13.2\% (Krahé and Berger, 2013). By comparison, perpetration rates are generally lower for women than for men (e.g., Struckman-Johnson, 1988; D'Abreu et al., 2013; Tomaszewska and Krahé, 2015), but it is clear that sexually aggressive behavior is not limited to males. Comparing prevalence rates of both sexual aggression perpetration and victimization, many studies found a substantial gap, with higher prevalence rates for sexual victimization (Kolivas and Gross, 2007, for a review).
Although the majority of large-scale studies focused on female victims and male perpetrators (e.g., WHO, 2013; Abrahams et al., 2014), there is evidence to show that men may also be victims of sexual aggression (Peterson et al., 2011, for a review) and women may also be perpetrators (Fisher and Pina, 2013, for a review). In a cross-cultural study conducted in 10 European countries, college men and women reported sexual aggression victimization and perpetration since the legal age of consent in the respective country (Krahé et al., 2015). The overall rates for sexual victimization were $32.2 \%$ for women and $27.1 \%$ for men. With respect to the perpetration of sexual aggression, the overall rates were $16.3 \%$ for men and $5.0 \%$ for women across all countries. These results challenge traditional stereotypes about sexual aggression with women as victims and men as perpetrators. Therefore, a gender-inclusive approach to sexual aggression is necessary to capture all facets of sexual aggression and provide support to both female and male victims (Turchik et al., 2016).

Regarding the relationship constellation between victim and perpetrator, studies found consistently that sexual aggression more often involves victims and perpetrators known to each other than happening between complete strangers (Black et al., 2011; Lehrer et al., 2013a). With respect to situational facilitators of sexual aggression, alcohol has been found to be involved in about half of all incidents of sexual assault (see Abbey et al., 2004, for a review), especially when victim and perpetrator are not well-acquainted (Ullman et al., 1999; Abbey et al., 2003). Alcohol increases the risk of both perpetration and victimization through its pharmacological effects by impairing information processing, such as attention to norms prohibiting the use of coercion or attention to danger signals. Alcohol also increases the risk of sexual aggression through its psychological effects, such as the activation of stereotyped beliefs about drinking alcohol as a cue indicating sexual availability and the risk of men overestimating women's sexual interest (Abbey et al., 2004).

\section{Sexual Aggression among College Students in Chile}

As noted above, there is a large body of research on sexual aggression in Western countries, highlighting its prevalence and costs for individuals and society. By contrast, data from Chile on sexual aggression victimization and perpetration, particularly among young adults, is limited. In Chile, the Catholic Church is a strong source of influence on social norms and public policy, in particular referring to sexuality (Lehrer et al., 2009; Morán Faúndes, 2013). For example, abortion is illegal under any circumstances, including incest or rape (Amnesty International, 2015), and divorce, which was not legalized until 2004, is opposed by the Catholic Church (Blofield, 2006). Despite this strong influence of the Catholic Church, norms and sexual life style of young adults have been changing over the last decades, which is reflected, for instance, in a younger age at sexual initiation (INJUV, 2013) and a higher number of sexual partners among women (González et al., 2007). These changes in sexual lifestyle make the study of sexual 
aggression perpetration and victimization in Chile even more critical.

To date, there are three published data sets on sexual assault victimization among college students in Chile (Maida et al., 2003; Lehrer et al., 2013a; Ilabaca et al., 2015), which produced similar prevalence rates. In a study conducted in Northern Chile, 28.7\% of female and $17.6 \%$ of male participants reported at least one experience of sexual victimization (Ilabaca et al., 2015). In a survey on college students' wellbeing in Santiago, 31\% of women and $20 \%$ of men reported that they had been made to engage in unwanted sexual activities since the age of 14 (Lehrer et al., 2013a). The third study with fifth-year medical students from Santiago revealed a victimization rate during medical school of $26.4 \%$ across both gender groups (separate rates for men and women were not reported; Maida et al., 2003). All three studies only collected victimization reports.

Although the three data sets have yielded important information about the prevalence of sexual victimization in college student samples, the current state of knowledge about sexual aggression in Chile remains limited in several respects. First, no studies are available that obtained reports of sexual aggression perpetration, even though such studies would provide relevant information about the problem of sexual aggression and the relationship between sexual aggression victimization and perpetration. Second, the definitions of sexual aggression varied substantially between the three studies. Maida et al. (2003) applied a broad definition of sexual abuse which included verbal sexual harassment, whereas Ilabaca et al. (2015) and Lehrer et al. (2013b) considered three specific coercive strategies, namely physical force, use of alcohol and/or drugs, and verbal pressure. Third, Lehrer et al. (2013a) and Maida et al. (2003) used only a limited number of items to assess sexual victimization, which may underestimate prevalence rates (Koss, 1993). Fourth, the three studies varied with regard to the time period for which sexual victimization reports were collected, considering only the time in college (Maida et al., 2003), the period since age 14 (Lehrer et al., 2013a), or specifying no timeframe at all (Ilabaca et al., 2015). It is obvious that this heterogeneity undermines the comparability of the findings across studies.

\section{The Current Study}

The available evidence leaves many questions about sexual aggression among college students in Chile unanswered, in particular referring to sexual aggression perpetration. Therefore, the aim of the current study was to examine the prevalence rates of sexual aggression perpetration and victimization in heterosexual encounters since the legal age of consent in a large sample of college students in Chile. In Chile, the age of consent for heterosexual sexual activities is 14 years, similar to other South American countries, such as Brazil and Colombia. However, the age of consent differs across countries around the world, ranging between 14 and 18 years in the majority of countries.

We used the Sexual Aggression and Victimization Scale (Krahé and Berger, 2013), which is available in Spanish, validated in cross-cultural research, and provides a detailed assessment of sexual aggression victimization and perpetration:
It combines three coercive strategies (use or threat of physical force, exploitation of the victim's inability to resist, e.g., due to alcohol or drug use, and use of verbal pressure) with three victim-perpetrator constellations (current or former partners, friends/acquaintances, and strangers). For each combination of coercive strategy and victim-perpetration relationship, four sexual acts are presented (sexual touch, attempted sexual intercourse, completed sexual intercourse, and other sexual activities, such as oral sex). This instrument enabled us to conduct a first comprehensive analysis of sexual aggression victimization and perpetration among college students in Chile. Because our focus was on nonconsensual sexual contacts, we excluded all forms of sexual transgression where lack of consent is not a defining feature, that is sexual contacts with a child under the age of consent and sexual contacts with a person between the ages of 14 and 18 exploiting a relationship of care, where consent is also not an issue as per article 363 of the Chilean penal code.

Based on previous studies showing higher victimization rates for women than for men, we expected that prevalence rates for sexual victimization would be higher for women than for men, and that women would experience more severe forms of sexual victimization. Additionally, we predicted that more women than men would be sole victims, i.e., they would report only victimization but no perpetration (Hypothesis 1). By contrast, we expected that more men than women would report sexual aggression perpetration, that men would report more severe forms of perpetration and that more men than women would be sole perpetrators, i.e., they would report only perpetration but no victimization (Hypothesis 2). Regarding the relationship between victim and perpetrator, we predicted that sexual aggression victimization and perpetration would be more common between (ex-)partners and friends/acquaintances than between strangers (Hypothesis 3). Since past research has shown that alcohol is involved in at least half of all sexually aggressive incidents, we expected a similar pattern in our sample (Hypothesis 4). In addition, we predicted that alcohol consumption would be more common in incidents of sexual aggression victimization and perpetration between strangers than between (ex-)partners and friends/acquaintances (Hypothesis 5). Finally, by assessing both sexual aggression victimization and perpetration, we wanted to examine the prevalence of being both a victim and a perpetrator of sexual aggression.

\section{MATERIALS AND METHODS}

\section{Participants}

The initial sample consisted of $N=1310$ participants (988 female, 322 male) recruited from five public and private universities located in the Santiago Metropolitan and Valparaíso Region in Chile. From this sample, participants below the age of 18 or 30 years or older were excluded $(n=47)$ because the study was designed to investigate sexual aggression among young adults. A total of 127 participants identified themselves as gay/lesbian ( 30 women and 39 men) or bisexual (44 women and 14 men). These subgroups were also excluded because heterosexual participants reported a higher age at first sexual intercourse compared to gay/lesbian participants and a lower 
number of sexual partners compared to bisexual participants. Moreover, gay/lesbian and bisexual participants differed in their sexual behavior, with bisexuals reporting more sexual partners. Therefore, we decided against merging these groups with the large heterosexual sample. We also decided against calculating separate prevalence rates for gay/lesbian and bisexual participants, respectively, as the two groups were too small to yield reliable conclusions. One female participant was excluded because she did not respond to any of the victimization and perpetration items.

The final sample consisted of $N=1135$ participants ( 885 female, 250 male), almost all of whom were college students (97.2\%) and Chilean nationals (98.6\%). The mean age was 22.0 years $(S D=2.62$, range $18-29$ years). Men were significantly older $(M=22.4$ years, $S D=2.68)$ than women $(M=21.8$ years, $S D=2.59), t_{(1125)}=-3.01, p<0.01$. Nearly all participants (95.5\%) reported non-coital sexual experiences, such as kissing and touching, and $86.3 \%$ of the sample had coital experience. The mean age of first sexual intercourse among the participants with coital experience was 17.2 years $(S D=2.21)$. The majority of participants $(92.1 \%)$ had been in a relationship in the past or were in a relationship at the time of the survey. Men reported more sexual partners $(M=2.8, S D=3.10)$ than $\operatorname{did}$ women $(M=2.0$, $S D=2.25), t_{(277)}=-3.71, p<0.001$.

\section{Measures}

\section{Sexual Aggression Victimization and Perpetration}

To assess female and male prevalence rates for experiencing and engaging in sexual aggression, the Sexual Aggression and Victimization Scale (SAV-S, Krahé and Berger, 2013) was used. The SAV-S was previously applied in 10 countries, including Spain, and validated by cross-cultural research conducted in several European countries (Krahé et al., 2015, 2016). Similar to the widely used Sexual Experience Survey Short Form (SES-SF, Koss et al., 2007), the SAV-S includes different coercive strategies and specific sexual acts. Unlike the SES, it provides a more detailed picture of the relationship context of sexual assault by assessing, for each specific coercive strategy and sexual act, the relationship between the victim and the perpetrator.

We used a Spanish version of the SAV-S, which had already been used and validated in Spain (Krahé et al., 2015, 2016). Speakers of Chilean Spanish adapted the scale to countryspecific language usage. A Chilean Spanish version of the remaining items, originally in German, was created by using the back-translation approach. This involved the translation of the German items into Chilean Spanish by a native speaker of Chile, which were then translated back into German by a native speaker of German.

The items assessing sexual aggression victimization and perpetration are constructed in a parallel way. Three coercive strategies are presented: the use or threat of physical force, the exploitation of the victim's inability to resist (e.g., due to alcohol consumption or drug use), and verbal pressure (e.g., by threatening to end the relationship). After each coercive strategy, three different relationship constellations between the victim and the perpetrator are presented: current or former partner, friend or acquaintance, and stranger. Within each relationship constellation, four sexual acts are presented: sexual touch, attempted sexual intercourse, completed sexual intercourse, and other sexual acts (e.g., oral sex). This cross-classification of coercive strategies, victim-perpetrator relationships, and sexual acts resulted in 36 items each for the victimization and perpetration parts of the SAV-S. Following ethical standards and previous studies (Krahé et al., 2015), participants were asked about victimization first before being prompted to indicate perpetration behavior.

For each item, participants provided frequency ratings on a three-point scale: never (0), once (1), or more than once $(>1)$. Responses were elicited for two time periods: (1) since the age of 14, which represents the legal age of consent for heterosexual sexual contacts in Chile, until 12 months ago, and (2) in the last 12 months. The two time windows correspond to the time periods used by the Sexual Experiences Survey (Koss et al., 2007). The lower age limit of 14 was required to be able to distinguish non-consensual sexual activities from child sexual abuse, where consent is not an issue.

\section{Situational Drinking Behavior}

Participants who reported at least one incident of experiencing or engaging in sexual aggression for a particular relationship constellation were asked if alcohol had been consumed in the situation(s) by themselves (1), the other person (2), by both of them (3), or not at all (4).

\section{Sexual Orientation and Experience}

Participants' sexual orientation was assessed by presenting three options: heterosexual, homosexual, and bisexual. Regarding past sexual behavior, participants were asked to indicate (yes/no) if they had consensual non-coital experiences (e.g., kissing and touching) and had had sexual intercourse. If they reported sexual intercourse, they were asked to indicate their age at first sexual intercourse and the number of partners with whom they had sexual intercourse, separately for steady relationships and casual sexual encounters.

\section{Demographic and Relationship Information}

Participants were asked to indicate their sex (male or female), age, nationality, college student status (yes/no), if they had ever been in a relationship, and if they were in a relationship at the time of the study (yes/no).

\section{Procedure}

Approval of the study protocol and all instruments was obtained from the institutional review boards of the authors' universities. The data were collected in an online survey during the second semester of 2015. To recruit participants, information about the study was presented in classes with the approval of the head of department and the instructor, and e-mail addresses of interested students were collected on a voluntary basis to send them the link to the survey. The study was also advertised via institutional e-mail lists, flyers distributed on campuses, and invitations through social media university groups. Participants were required to give active consent on the first page of the questionnaire before being able to proceed to the items.

To account for the possibility that responding to the items might cause distress, a "help button" was provided on each page of the victimization and perpetration questions, which 
opened a new browser window with information about local counseling centers specializing in sexual violence. This approach follows recommendations of good practice in research on sexual aggression (Krahé and Vanwesenbeeck, 2016). In return for participation, participants were invited to take part in a raffle of gift cards worth $\$ 5000$ CLP (\$7 USD). For this, participants were asked to indicate their e-mail address on a new browser page so that it was stored separately from their answers, ensuing full anonymity.

\section{Plan of Analysis}

If participants responded never to all victimization items, they were categorized as non-victims (coded 0 ). If they reported at least one incident of sexual victimization, they were categorized as victim (coded 1). Perpetration status was coded in the same way. To arrive at a score of lifetime prevalence of sexual aggression victimization and perpetration for each participant, we combined the two time periods.

Because the data were non-normally distributed, we decided to apply non-parametric statistics. Accordingly, for Hypotheses 1 and 2, gender differences in rates for sexual aggression victimization and perpetration and in the sole victimization and perpetration groups were tested through Pearson's chi square test. Since multiple responses to the victimization and perpetration items were possible, differences in the frequency of relationship constellations in sexually aggressive incidents and alcohol consumption predicted in Hypotheses 3 and 5 could not be tested for significance.

\section{RESULTS}

\section{Prevalence of Sexual Aggression Victimization}

Across all coercive strategies, victim-perpetrator constellations, and sexual acts, $51.9 \%$ of women and $48.0 \%$ of men reported sexual victimization since the age of 14 . Prevalence rates of sexual victimization broken down by sex, coercive strategy, and victim-perpetrator relationship are presented in Table $\mathbf{1 .}$ The gender difference in the overall rate was non-significant, $\chi_{(1, N=1135)}^{2}=1.17, p=0.280$, disconfirming Hypothesis 1.
Looking at specific combinations of coercive strategy and victimperpetrator relationship, only one significant gender difference was found: More men (14.6\%) than women (8.3\%) reported sexual victimization by a stranger through the use of verbal pressure, $\chi_{(1, N=1103)}^{2}=8.80, p<0.01$. In the Supplementary Material, we provide tables for the prevalence rates of sexual victimization broken down by sex, coercive strategy, victimperpetrator relationship, and sexual acts, combined for the two time windows (i.e., since the age of 14) and for the separate time periods (Table 1_Suppl. for sexual victimization for both time periods combined/since the age of 14, Table 2_Suppl. for sexual victimization since the age of 14 up to 12 months ago, Table 3_Suppl. for sexual victimization in the last 12 months).

To examine the gender difference in the severity of participants' victimization experiences predicted in Hypothesis 1, we adopted the scoring proposed by Koss et al. (2008). They created a non-redundant six level classification of increasing severity ranging from no victimization to rape: (1) No victimization includes all participants who did not report any form of sexual victimization. (2) Sexual contact describes sexual touching without penetration (e.g., kissing, fondling) but excludes the more severe forms of sexual victimization. (3) Attempted coercion refers to attempted anal, oral, or vaginal penetration using verbal pressure but excludes coercion, attempted, or completed rape. (4) Coercion describes verbally pressured anal, oral, or vaginal penetration but excludes attempted or completed rape. (5) Attempted rape refers to attempted anal, oral, or vaginal penetration through the use or threat of physical force or the exploitation of the victim's incapacitated state but excludes completed penetration. (6) Rape describes anal, oral, or vaginal penetration by using or threatening to use physical force or exploiting the victim's inability to resist. Table 2 presents the prevalence rates of sexual victimization according to this classification for female and male participants.

The findings show that the high overall rates of sexual victimization are due to the high prevalence of completed rape, which was reported by $30.7 \%$ of female and $32.4 \%$ of male participants. The remaining categories had much lower frequencies. Women and men did not differ in the overall

TABLE 1 | Sexual aggression victimization in percent since age 14, broken down by sex, coercive strategy, and victim-perpetrator relationship, $N=1135$ ( $\mathrm{nf}=885, \mathrm{~nm}=250$ ).

\begin{tabular}{|c|c|c|c|c|c|c|c|c|}
\hline \multirow[t]{3}{*}{ Victim-Perpetrator relationship } & \multicolumn{6}{|c|}{ Coercive strategy } & & \\
\hline & \multicolumn{2}{|c|}{$\begin{array}{l}\text { Use/threat of } \\
\text { physical force }\end{array}$} & \multicolumn{2}{|c|}{$\begin{array}{l}\text { Exploitation of } \\
\text { inability to resist }\end{array}$} & \multicolumn{2}{|c|}{$\begin{array}{c}\text { Verbal } \\
\text { pressure }\end{array}$} & \multicolumn{2}{|c|}{$\begin{array}{c}\text { Total relationship } \\
\text { (at least one }>=1 \text { per row) }\end{array}$} \\
\hline & Women & Men & Women & Men & Women & Men & Women & Men \\
\hline (Ex-)Partner & 26.3 & 27.2 & 18.3 & 17.3 & 22.1 & 17.5 & 36.0 & 34.8 \\
\hline Friend/Acquaintance & 24.7 & 24.8 & 21.0 & 19.8 & 12.4 & 13.8 & 32.1 & 32.8 \\
\hline Stranger & 17.7 & 20.0 & 16.4 & 16.5 & $8.3^{*}$ & $14.6^{\star}$ & 23.7 & 25.2 \\
\hline Total coercive strategy (at least one $>=1$ per column) & 43.0 & 39.2 & 34.7 & 29.0 & 29.1 & 26.0 & 51.9 & 48.0 \\
\hline
\end{tabular}

Gender difference: ${ }^{*} p<0.01$. Multiple responses were possible. 
distribution or on any of the individual categories, disconfirming Hypothesis 1.

With respect to the relationship between victimization and perpetration, within the victimized group, $55.0 \%$ of men and $70.2 \%$ of women were sole victims, that is they only experienced sexual victimization and did not report perpetration, the remaining $45 \%$ of men and $29.8 \%$ of women in the victimization group also reported some form of perpetration. The gender difference was significant, $\chi_{(1, N=573)}^{2}=9.91, p<0.01$, confirming Hypothesis 1.

\section{Prevalence of Sexual Aggression Perpetration}

The overall prevalence rates of sexual aggression perpetration since the age of 14 across all coercive strategies, relationship constellations, and sexual acts were $16.5 \%$ for women and $26.8 \%$ for men. Table 3 shows the prevalence rates for sexual aggression perpetration broken down by sex, coercive strategies, and victim-perpetrator relationship. In line with Hypothesis 2 , the gender difference in the overall perpetration rate was significant, $\chi_{(1, N=1121)}^{2}=13.40, p<0.001$. With respect to gender differences for specific constellations of coercive strategy and relationship, more men than women reported sexual aggression perpetration toward a friend or acquaintance through threatening or using physical force, $\chi_{(1, N=1104)}^{2}=8.33$, $p<0.01$, and through exploiting the victim's inability to

TABLE 2 | Sexual aggression victimization in percent since age 14 based on the scoring proposed by Koss et al. (2008), $N=1135$ ( $\mathrm{nf}=885$, $\mathrm{nm}=250$ ).

\begin{tabular}{lcc}
\hline & \multicolumn{2}{c}{ Sexual victimization } \\
\cline { 2 - 3 } & Women & Men \\
\hline No victimization & 48.1 & 52.0 \\
Sexual contact & 10.7 & 8.4 \\
Attempted coercion & 1.1 & 0.0 \\
Coercion & 3.5 & 4.4 \\
Attempted rape & 5.8 & 2.8 \\
Rape & 30.7 & 32.4
\end{tabular}

resist, $\chi_{(1, N=1096)}^{2}=8.77, p<0.01$. More men than women reported sexual aggression perpetration toward a stranger through exploiting his/her inability to resist, $\chi_{(1, N=1096)}^{2}=9.74$, $p<0.01$. In the Supplementary Material, we provide tables for the prevalence rates of sexual aggression perpetration broken down by sex, coercive strategy, victim-perpetrator constellation, and sexual acts, since the age of 14 and for the separate time periods (Table 4_Suppl. for sexual perpetration for both time periods combined/since the age of 14, Table 5_Suppl. for sexual perpetration since the age of 14 up to 12 months ago, Table 6_Suppl. for sexual perpetration in the last 12 months).

Comparing sexual aggression victimization and perpetration, prevalence rates were significantly higher for victimization among both men [48.0\% victimization vs. $26.8 \%$ perpetration, $\left.\chi_{(1, N=250)}^{2}=38.97, p<0.001\right]$ and women [51.9\% victimization vs. $16.5 \%$ perpetration, $\left.\chi_{(1, N=871)}^{2}=120.43, p<0.001\right]$.

To test the gender difference in the severity of sexual assault perpetration proposed in Hypothesis 2, we applied the six-level classification of severity by Koss et al. (2008) to the perpetration reports and categorized all participants according to their most severe form of perpetration reported. The results of this classification are presented in Table 4. For the overall distribution of the six-level scores, a significant gender difference was found, $\chi_{(5, N=1121)}^{2}=18.17, p<0.01$, confirming Hypothesis 2 . At the level of the different categories, significantly more women than men fell into the non-perpetrator category, whereas at the other end of the severity spectrum, significantly more men than women reported rape.

In the perpetration group, $19.4 \%$ of men and $6.3 \%$ of women were sole perpetrators, i.e., they reported perpetration but no victimization, whereas the majority of perpetrators $(80.6 \%$ of men and $93.8 \%$ of women) also reported victimization. The gender difference was significant, $\chi_{(1, N=211)}^{2}=8.47, p<0.01$, supporting Hypothesis 2.

\section{Victim-Perpetrator Relationship and Coercive Strategies}

With respect to the relationship between victim and perpetrator, sexual victimization by a current or former partner was reported

TABLE 3 | Sexual aggression perpetration in percent since age 14, broken down by sex, coercive strategy, and victim-perpetrator relationship, $N=1121$ $(\mathrm{nf}=871, \mathrm{~nm}=250)$.

\begin{tabular}{|c|c|c|c|c|c|c|c|c|}
\hline \multirow[b]{3}{*}{ Victim-Perpetrator relationship } & \multicolumn{6}{|c|}{ Coercive strategy } & & \\
\hline & \multicolumn{2}{|c|}{$\begin{array}{l}\text { Use/threat of } \\
\text { physical force }\end{array}$} & \multicolumn{2}{|c|}{$\begin{array}{l}\text { Exploitation of } \\
\text { inability to resist }\end{array}$} & \multicolumn{2}{|c|}{ Verbal pressure } & \multicolumn{2}{|c|}{$\begin{array}{c}\text { Total relationship } \\
\text { (at least one }>=1 \text { per row) }\end{array}$} \\
\hline & Women & Men & Women & Men & Women & Men & Women & Men \\
\hline (Ex-)Partner & 5.0 & 8.5 & 4.2 & 7.3 & 7.3 & 10.7 & $11.7^{\star \star}$ & $19.6^{\star \star}$ \\
\hline Friend/acquaintance & $4.0^{\star \star}$ & $8.5^{\star \star}$ & $4.5^{\star \star}$ & $9.4^{\star *}$ & 3.7 & 5.4 & $8.3^{\star \star}$ & $14.9^{\star \star}$ \\
\hline Stranger & 3.5 & 4.5 & $2.5^{\star \star}$ & $6.6^{\star \star}$ & 1.8 & 3.7 & 5.1 & 7.6 \\
\hline Total coercive strategy (at least one $>=1$ per column) & 8.6 & 12.9 & $7.7^{\star}$ & $13.0^{*}$ & 9.1 & 12.0 & $16.5^{\star \star \star}$ & $26.8^{\star \star \star \star}$ \\
\hline
\end{tabular}

Gender differences: ${ }^{\star} p<0.017,{ }^{\star \star} p<0.01,{ }^{* \star *} p<0.001$. Multiple responses were possible. 
TABLE 4 | Sexual aggression perpetration in percent since age 14 based on the scoring proposed by Koss et al. (2008), $N=1121$ ( $\mathrm{nf}=871, \mathrm{~nm}=$ 250).

\begin{tabular}{lcc}
\hline & \multicolumn{2}{c}{ Sexual aggression perpetration } \\
\cline { 2 - 3 } & Women & Men \\
\hline No perpetration & $83.5^{\star \star \star}$ & $73.2^{\star \star \star}$ \\
Sexual contact & 5.3 & 6.4 \\
Attempted coercion & 0.6 & 0.4 \\
Coercion & 2.9 & 3.6 \\
Attempted rape & 1.5 & 3.2 \\
Rape & $6.3^{\star \star \star}$ & $13.2^{\star \star \star}$ \\
\hline
\end{tabular}

Gender differences: ${ }^{* \star *} p<0.001$.

by $36.0 \%$ of women and $34.8 \%$ of men. A similar percentage of women $(32.1 \%)$ and men $(32.8 \%)$ reported victimization by a friend or acquaintance, and the lowest rates were found for victimization by strangers, reported by $23.7 \%$ of women and $25.2 \%$ of men. For sexual aggression perpetration, $19.6 \%$ of men and $11.7 \%$ of women reported sexual aggression perpetration toward a current of former partner, followed by a friend or acquaintance (14.9\% of men and $8.3 \%$ of women). The lowest prevalence rates were found for sexual aggression perpetration toward a stranger, reported by $7.6 \%$ of men and $5.1 \%$ of women. These findings confirm Hypothesis 3.

Gender differences within each relationship constellation were tested with a corrected alpha level of $p<0.05 / 3$ (critical $p=0.017)$ to account for separate tests for the three victimperpetrator constellations. For sexual victimization, the gender differences were nonsignificant, with $\chi_{(1, N=1135)}^{2}=0.13, p=$ 0.717 for current or former partners, $\chi_{(1, N=1135)}^{2}=0.05, p=$ 0.832 for friends/acquaintances, and $\chi_{(1, N=1135)}^{2}=0.23, p=$ 0.631 for strangers. Regarding sexual aggression perpetration, more men than women reported sexually aggressive behavior toward a current or former partner, $\chi_{(1, N=1121)}^{2}=10.37, p<$ 0.01 , and toward a friend or acquaintance, $\chi_{(1, N=1120)}^{2}=9.58$, $p<0.01$. No gender difference was found for sexually aggressive behaviors toward strangers, $\chi_{(1, N=1120)}^{2}=2.43, p=0.119$.

Regarding victimization, the most prevalent coercive strategy was the use or threat of physical force, reported by $43.0 \%$ of women and $39.2 \%$ of men, followed by exploitation of the inability to resist, reported by $34.7 \%$ of women and $29.0 \%$ of men, and verbal pressure, reported by $29.1 \%$ of women and $26.0 \%$ of men. Gender differences were tested across the three coercive strategies using a corrected alpha-level of $p=0.05 / 3$. No significant gender differences were found for the three coercive strategies, $\chi_{(1, N=1132)}^{2}=1.14, p=0.287$ for physical force, $\chi_{(1, N=1121)}^{2}=2.80, p=0.095$ for exploitation, and $\chi_{(1, N=1109)}^{2}=0.89, p=0.346$ for verbal pressure.

With respect to sexual aggression perpetration, the prevalence rates for the three coercive strategies (use or threat of physical force, exploitation of the victim's inability to resist, and verbal pressure) were similar, ranging between 12.0 and $13.0 \%$ for men and between 7.7 and $9.1 \%$ for women. Gender differences within each coercive strategy were examined using a corrected alpha level of $p<0.05 / 3$ (critical $p=0.017$ ). Paralleling our findings for sexual victimization, men and women did not differ in their use or threat of physical force, $\chi_{(1, N=1109)}^{2}=4.14, p=0.042$, and verbal pressure, $\chi_{(1, N=1095)}^{2}=1.72, p=0.189$. By contrast, more men than women reported having exploited the victim's inability to resist, $\chi_{(1, N=1100)}^{2}=6.56, p<0.017$.

\section{Alcohol Use}

Regarding alcohol consumption in incidents of sexual victimization, $63.6 \%$ of women and $70.0 \%$ of men reported that they, the perpetrator, or both had drunk alcohol in at least one of the reported incidents. With respect to sexual aggression perpetration, about half of the female (48.6\%) and male $(53.7 \%)$ perpetrators indicated that alcohol had been consumed by themselves, the other person, or both, in the situations in which they had shown sexually aggressive behavior. These findings are consistent with Hypothesis 4. The gender differences were not significant, $\chi_{(1, N=579)}^{2}=1.70, p=0.192$ for victimization and $\chi_{(1, N=209)}^{2}=0.48, p=0.488$ for perpetration.

As predicted in Hypothesis 5, the use of alcohol was more common in victimization and perpetration incidents involving a stranger $(79.5 \%$ of women and $84.1 \%$ of men who reported victimization by a stranger and $68.2 \%$ of women and $89.5 \%$ of men who reported having engaged in sexual aggression toward a stranger indicated that alcohol was consumed) than in incidents involving a friend or acquaintance (victims: $62.9 \%$ of women and $70.7 \%$ of men; perpetrators: $50.0 \%$ of women and $62.2 \%$ of men) and an (ex-)partner (victims: $40.9 \%$ of women and $51.7 \%$ of men; perpetrators: $31.3 \%$ of women and $40.8 \%$ of men). No significant gender differences were found. These findings are consistent with Hypothesis 5 that alcohol is primarily involved in incidents of sexual aggression in which the victim and the perpetrator are strangers.

\section{DISCUSSION}

The purpose of the present study was to provide detailed evidence on the prevalence of sexual aggression victimization and perpetration since the age of consent (i.e., 14 years) in a large sample of college students in Chile. Additionally, we explored the role of alcohol in incidents of victimization and perpetration. By collecting reports of both victimization and perpetration from male and female participants, our study adopted a genderinclusive approach to the study of sexual aggression (Turchik et al., 2016). The age range of our sample was $18-29$ years.

Regarding participants' sexual experience background, almost all participants (95.5\%) reported non-coital experiences, such as sexual touching and kissing, and $86.4 \%$ of the sample reported coital experience. The latter rate was higher than in past studies with young adults in Chile, which provided estimates between 65 and 71\% (Lehrer et al., 2009, 2013b; INJUV, 2013). This difference may be due to the age range of our study starting at 18 years, compared to the study by INJUV (2013), which included participants from the age of 15 , but it may also reflect an ongoing liberalization of sexual attitudes and behavior, because 
the estimates provided by Lehrer et al. $(2009,2013 \mathrm{~b})$ were based on a study conducted in 2005. In terms of the onset of coital activities, age at first sexual intercourse in our sample (17.2 years) was similar to figures from past national research and findings from Western countries (Durex, 2005; Barrientos, 2010; Reissing et al., 2012).

Across all coercive strategies, victim-perpetrator relationships, and sexual acts, $51.9 \%$ of women and $48.0 \%$ of men reported sexual aggression victimization. These rates were higher than previous findings from college student samples in Chile (Maida et al., 2003; Lehrer et al., 2013a; Ilabaca et al., 2015), which may be attributed to the more detailed and behaviorally specific assessment of sexual victimization that permits a better detection of nonconsensual sexual experiences (cf., Koss, 1993). Crosscultural research from Europe found similar victimization rates for both male and female college students in Greece (55.8\% for men and $45.5 \%$ for women), for men in Cyprus (49.0\%), and for women in the Netherlands (52.2\%; Krahé et al., 2015). Regarding the severity of victimization incidents, it is noteworthy that the highest prevalence rates were found for rape rather than for less severe forms, such as sexual contact. This finding indicates that if sexual aggression occurs, it is likely to take the most severe form, namely rape, rather than showing a pattern of higher frequencies for the less severe forms of sexual aggression.

With respect to the perpetration of sexually aggressive behavior, the overall perpetration rates were $26.8 \%$ for men and $16.5 \%$ for women, constituting the first estimates for college students in Chile. In cross-cultural research, similar prevalence rates were obtained in college students samples from Australia (25.0\% of men, $12.7 \%$ of women) and Singapore $(27.0 \%$ of men, $19.3 \%$ of women; both countries included in Chan et al., 2008) as well as from Turkey (28.9\% of men, $14.2 \%$ of women; Schuster et al., 2016). Again, the highest prevalence rates were found for the most severe form of sexual aggression perpetration, namely rape.

Looking at sexual aggression victimization and perpetration in combination, we found victimization rates to be substantially higher than perpetration rates in both gender groups (for women: $51.9 \%$ victimization vs. $16.5 \%$ perpetration; for men: $48.0 \%$ victimization vs. $26.8 \%$ perpetration). This discrepancy confirms the substantial difference in self-reports about victim and perpetrator behavior reported by past studies (e.g., Kolivas and Gross, 2007; Krahé and Berger, 2013). It may be related to the fact that perpetration behavior is socially disapproved and the possibility that perpetrators may have multiple victims. The finding that the reporting discrepancy held for both men and women speaks against the explanation that it is due to men's misinterpretation or overestimation of female friendliness as a sexual interest cue (Abbey, 1982; Perilloux et al., 2015). Instead, it is consistent with the alternative explanation that victims have first-hand knowledge of their lack of consent, whereas perpetrators need to infer non-consent from the victim's verbal statements and behavior (Kolivas and Gross, 2007).

Concerning gender differences, our prediction in Hypothesis 1 that more women than men would report sexual victimization, was not supported. Overall, there was no significant difference between the prevalence rates for men and women, and the differentiation of sexual victimization experiences by severity did not show gender differences either. Prevalence rates broken down by coercive strategy and relationship constellation revealed only one significant gender difference, with more men than women reporting sexual victimization through verbal pressure by a stranger. This finding may be related to traditional gender stereotypes which assume that men are always willing to have sex. Hence, if a woman wants to have sexual contact with a male stranger, he may be less willing to express refusal and/or she may be less likely to accept his refusal as genuine.

The absence of gender differences in sexual aggression victimization found in our study is contrary to a large body of Western research which has shown higher victimization rates for women than for men (e.g., Breiding et al., 2014; Cantor et al., 2015). However, the findings are consistent with several recent studies from the cross-cultural literature that also found no or only few gender differences (e.g., Brazil: D’Abreu et al., 2013; U.S.: Hines et al., 2012; Turkey: Schuster et al., 2016; Poland: Tomaszewska and Krahé, 2015) or even higher victimization rates among men compared to women (Krahé et al., 2015), challenging traditional views and stereotypes about sexual aggression victimization. More research is needed to understand social processes, cultural variables, sexuality related cognitions (e.g., sexual scripts, sexual self-esteem) as well as risky sexual behavior which may explain the absence of gender differences in victimization, particularly in the non-Western countries.

Although, we did not find many gender differences in the prevalence of sexual victimization, the psychological impact of sexual victimization may be different for women and men. More research is needed to examine the possibility that women may be more adversely affected by the experience of sexual victimization compared to men, possibly as a result of the imbalance of physical strength. The current body of evidence comparing the psychological consequences of sexual assault for male and female victims is limited and does not provide a conclusive picture. Whereas some studies found more negative effects on women, others found no gender difference, and yet others more adverse effects on men (see Peterson et al., 2011, for a review). Future research is needed to clarify the issue of whether sexual assault victimization has a different impact on female and male victims.

As predicted in Hypothesis 2, more men than women reported the perpetration of sexually aggressive behavior, which is in line with past international evidence (Krahé and Berger, 2013; Williams et al., 2014). For prevalence rates according to the level of severity, men also reported more sexual aggression perpetration than women, except for attempted coercion $(0.4 \%$ of men and $0.6 \%$ of women), but the gender difference was only significant for rape. Additionally, significantly more men (19.4\%) than women $(6.3 \%)$ reported being sole perpetrators, i.e., they only reported perpetration but no victimization. This means that the number of participants who were perpetrators only was very low, and substantially lower than the number of participants who were victims only. Similar results were found by Russell and Oswald $(2001,2002)$ who showed that $62.9 \%$ of men and $80.8 \%$ of women in the perpetration group had also been sexually victimized. To explain the overlap of victim and perpetrator roles, 
longitudinal studies that can assess the temporal sequence of victimization and perpetration are needed.

With respect to victim-perpetrator relationship constellations, sexual aggression victimization and perpetration were more common between (ex-)partners and friends/acquaintances than between strangers, which was in line with Hypothesis 3 and past national and international evidence (e.g., Lehrer et al., 2013a; Tomaszewska and Krahé, 2015; Schuster et al., 2016). This indicates that sexual aggression is more prevalent among persons who know each other than between unknown parties, disconfirming stereotyped views on sexual aggression.

Several cultural factors may have contributed to the high male and female victimization rates. First, although sex education is part of formal education in Chile (Ministerio de Salud Subsecretaría de Salud Pública, 2010), it focuses mainly on biological aspects of reproduction and disregards emotional dimensions, pleasure, sexual diversity, and sexual violence (Macintyre et al., 2015). Other potential sources of information may also be limited or provide a view of sexuality influenced by myths and cultural taboos (Macintyre et al., 2015). Another source of information, in particular for men, is pornography (Macintyre et al., 2015), which is associated with genderstereotypical beliefs about sexuality and with experiencing and engaging in sexual aggression (Peter and Valkenburg, 2016, for a review). Accordingly, young adults' knowledge about sexuality is limited (Barrientos Delgado and Silva Segovia, 2014), which may compromise their sense of sexual self-determination as well as their respect for the rights of their partners. Second, despite a general liberalization of sexuality (González et al., 2007), which includes the acceptance of premarital sexual intercourse and greater sexual autonomy for women (Barrientos Delgado and Silva Segovia, 2014), double standards for male and female sexuality still prevail. In particular, women who engage in casual sex are often regarded as "whores" or "easy," while the same does not apply to men (Barrientos Delgado and Silva Segovia, 2014). Thus, this image of women may undermine the respect for women's consent. At the same time, men are expected to be sexually active and experienced, and the social pressure to fulfill this expectation may undermine men's ability and confidence to reject unwanted sexual advances. Third, it is not unusual that young adults in Chile do not have an intimate space where they can engage in sexual intercourse (Barrientos Delgado and Silva Segovia, 2014), in particular those who are economically vulnerable or have more conservative parents. They have to rely on opportunities in which they can use rooms of friends, motels, cars, and public spaces, which may pressure them to have sex when these opportunities arise, potentially undermining respect for mutual consent. Fourth, adherence to the values of the Catholic Church, associated with later sexual initiation and fewer sexual partners (Pedersen, 2014), and the simultaneous exposure to information about very liberal sexual behavior in other parts of the world through globalization convey conflicting messages about sexual relationships. This may contribute to blurred boundaries between consensual sexual activities and sexual aggression.
Another cultural factor may be the high alcohol consumption and binge drinking rates among young adults in Chile (Saldivia and Vizcarra, 2012; Mason-Jones and Cabieses, 2015), given that alcohol is a substantial risk factor for sexual assault. In the present study, alcohol was consumed by one or both parties in at least half of all sexual aggression victimization and perpetration incidents, which is consistent with Hypothesis 4 and past research (Abbey et al., 2004, for a review). It is especially noteworthy that, in line with past research, the use of alcohol was more common between strangers than between (ex-)partners and friends/acquaintances, confirming Hypothesis 5. Alcohol consumption with its impairment of cognitive processes may promote the misinterpretation of another person's behaviors and cues as indicating sexual interest (Abbey et al., 2004), which is more likely to be the case among strangers. Accordingly, alcohol may lower the threshold for using sexual coercion, particularly if there is no emotional connection between perpetrator and victim. However, further culture-sensitive research is needed to confirm these tentative explanations and to understand how young adults' sexuality is shaped by cultural norms and expectations, including alcohol-related beliefs and behaviors. Such research should adopt a qualitative approach to gain a better understanding of the meaning and social construction of sexual aggression from both the victim and the perpetrator perspective (Krahé et al., 2016).

\section{Strengths and Limitations}

We believe that our study has several strengths. We were able to recruit a large sample of students from different public and private universities located in the Santiago Metropolitan and Valparaíso Region, where about half of the Chilean population lives (Comité Nacional de Estadísticas Vitales, 2015). Our study collected information about sexual aggression victimization and perpetration from both men and women, which means we were able to provide insights in the relationship between being a victim and engaging in sexually aggressive behavior. Additionally, the assessment of coercive strategies, relationship constellations between victim and perpetrator, and sexual acts yielded a detailed picture of sexual aggression victimization and perpetration in a country for which little previous evidence is available.

At the same time, several limitations have to be noted. The first is that we used a convenience sample, and future research is needed to determine whether similar prevalence rates are obtained in other samples of college students and young adults more generally. This limitation notwithstanding, it has been shown that convenience samples may yield valid conclusions (Straus, 2009). A second limitation was that women were overrepresented in the sample, which should be kept in mind when interpreting the male prevalence rates. Third, our initial sample included persons who described their sexual orientation as gay/lesbian or bisexual, however their number was too small to facilitate reliable analyses of prevalence rates. More research is needed both in Chile and internationally about the prevalence of sexual aggression victimization and perpetration among gay, lesbian, and bisexual persons since studies suggest that they may be a vulnerable group (see Rothman et al., 2011, for a 
review). Fourth, in assessing sexual aggression our focus was on nonconsensual sexual contacts. Therefore, we excluded all forms of sexual transgression where lack of consent is not a defining feature, i.e., childhood sexual abuse by any perpetrator under the age of 14 and sexual contacts by family members, which are based on the exploitation of a relationship of care. To cover all facets of sexual aggression, future research should consider to include family members and other perpetrators exploiting a position of trust or authority.

Despite these limitations, the current study provides new data about the prevalence of sexual aggression among college students in Chile, addressing the knowledge gap about victimization and, in particular, perpetration in this country. Consistent with studies from the international literature, sexual aggression was established to be a serious problem among college students, affecting a substantial proportion of women and men. The findings highlight the need to put sexual aggression on the policy agenda in Chile, documenting the need to develop and implement prevention programs, including the coverage of sexual aggression in formal sex education curricula. Furthermore, our findings contribute to the international data base on sexual aggression and provide a starting point for considering cultural variables that may allow a better understanding of young adults' sexuality and sexual aggression in different parts of the world.

\section{REFERENCES}

Abbey, A. (1982). Sex differences in attributions for friendly behavior: do males misperceive females' friendliness? J. Pers. Soc. Psychol. 42, 830-838.

Abbey, A., Clinton-Sherrod, A. M., McAuslan, P., Zawacki, T., and Buck, P. O. (2003). The relationship between the quantity of alcohol consumed and the severity of sexual assaults committed by college men. J. Interpers. Violence 18, 813-833. doi: $10.1177 / 0886260503253301$

Abbey, A., Zawacki, T., Buck, P. O., Clinton, A. M., and McAuslan, P. (2004). Sexual assault and alcohol consumption: what do we know about their relationship and what types of research are still needed? Aggress. Violent Behav. 9, 271-303. doi: 10.1016/S1359-1789(03)00011-9

Abrahams, N., Devries, K., Watts, C., Pallitto, C., Petzold, M., Shamu, S., et al. (2014). Worldwide prevalence of non-partner sexual violence: a systematic review. Lancet 383, 1648-1654. doi: 10.1016/S0140-6736(13)62243-6

Amnesty International (2015). Amnesty International Report 2014/15: The State of the World's Human Rights. Available online at: https://www.amnesty.org/en/ documents/pol10/0001/2015/en/

Barrientos, J. (2010). Sexual initiation for heterosexual individuals in northern Chile. Sex. Res. Soc. Policy 7, 37-44. doi: 10.1007/s13178-010-0007-0

Barrientos Delgado, J., and Silva Segovia, J. (2014). Sexual initiation of young people in Chile: a qualitative study. Int. J. Sex. Health 26, 172-185. doi: 10.1080/19317611.2013.852149

Black, M. C., Basile, K. C., Breiding, M. J., Smith, S. G., Walters, M. L., Merrick, M. T., et al. (2011). National Intimate Partner and Sexual Violence Survey: 2010 Summary Report. Atlanta, GA: National Center for Injury Prevention and Control, Centers for Disease and Control and Prevention. Available online at: http://www.cdc.gov/violenceprevention/pdf/nisvs_executive_summary-a.pdf

Blofield, M. (2006). The Politics of Moral Sin: Abortion and Divorce in Spain, Chile and Argentina. New York, NY: Routledge.

Breiding, M. J., Smith, S. G., Basile, K. C., Walters, M. L., Chen, J., and Merrick, M. T. (2014). Prevalence and Characteristics of Sexual Violence, Stalking, and Intimate Partner Violence Victimization - National Intimate Partner and Sexual Violence Survey, United States, 2011. Morbidity and Mortality Weekly Report, 1-18. Available online at: http://www.cdc.gov/mmwr/preview/ mmwrhtml/ss6308a1.htm

\section{AUTHOR CONTRIBUTIONS}

IS designed the study, collected, analyzed and interpreted the data, and wrote the article. BK provided input and supervision to the design of the study, analyses and interpretation of the data, and writing up the article. PI and JM helped with the process of obtaining ethics approval and with the data collection. All authors critically revised the manuscript, approved this version, and agreed to be accountable for all aspects of this work and its integrity.

\section{FUNDING}

The study was supported by a grant from the German Academic Scholarship Foundation (Studienstiftung des Deutschen Volkes) to the first author. We also gratefully acknowledge the support of the Deutsche Forschungsgemeinschaft (German Research Foundation) and the Open Access Publishing Fund of the University of Potsdam.

\section{SUPPLEMENTARY MATERIAL}

The Supplementary Material for this article can be found online at: http://journal.frontiersin.org/article/10.3389/fpsyg. 2016.01354

Cantor, D., Fisher, B., Chibnall, S., Townsend, R., Lee, H., Bruce, C., et al. (2015). Report on the AAU Campus Climate Survey on Sexual Assault and Sexual Misconduct. Availabe online at: http://sexualassaulttaskforce.harvard.edu/files/ taskforce/files/final_report_harvard_9.21.15.pdf

Chan, K. L., Straus, M. A., Brownridge, D. A., Tiwari, A., and Leung, W. C. (2008). Prevalence of dating partner violence and suicidal ideation among male and female university students worldwide. J. Midwifery Womens Health 53, 529-537. doi: 10.1016/j.jmwh.2008.04.016

Choudhary, E., Smith, M., and Bossarte, R. M. (2012). Depression, anxiety, and symptom profiles among female and male victims of sexual violence. Am. J. Mens Health 6, 28-36. doi: 10.1177/1557988311414045

Comité Nacional de Estadísticas Vitales (2015). Estadísticas Vitales, Anuario 2013 [Vital Statistics, Annual 2013]. Available online at: http://www.ine.cl/canales/ menu/publicaciones/calendario_de_publicaciones/pdf/completa_vitales_2013. pdf

D’Abreu, L. C. F., Krahé, B., and Bazon, M. R. (2013). Sexual aggression among Brazilian college students: prevalence of victimization and perpetration in men and women. J. Sex Res. 50, 795-807. doi: 10.1080/00224499.2012.702799

Dardis, C. M., Murphy, M. J., Bill, A. C., and Gidycz, C. A. (2016). An investigation of the tenets of social norms theory as they relate to sexually aggressive attitudes and sexual assault perpetration: a comparison of men and their friends. Psychol. Violence 6, 163-171. doi: 10.1037/a0039443

Durex (2005). Give and Receive: 2005 Global Sex Survey Results. Availabe online at: http://www.data360.org/pdf/20070416064139.Global Sex Survey.pdf

Fisher, B., Daigle, L. E., and Cullen, F. T. (2010). Unsafe in the Ivory Tower: The Sexual Victimization of College Women. Los Angeles, CA: Sage Publications.

Fisher, N. L., and Pina, A. (2013). An overview of the literature on femaleperpetrated adult male sexual victimization. Aggress. Violent Behav. 18, 54-61. doi: 10.1016/j.avb.2012.10.001

French, B. H., Tilghman, J. D., and Malebranche, D. A. (2015). Sexual coercion context and psychosocial correlates among diverse males. Psychol. Men Masc. 16, 42-53. doi: 10.1037/a0035915

González, E., Molina, T., Montero, A., Martínez, V., and Leyton, C. (2007). Comportamientos sexuales y diferencias de género en adolescentes usuarios de un sistema público de salud universitario [Sexual behavior and gender differences among adolescents consulting at a university public health 
system]. Rev. Méd. Chil. 135, 1261-1269. doi: 10.4067/S0034-988720070010 00005

Hines, D. A., Armstrong, J. L., Reed, K. P., and Cameron, A. Y. (2012). Gender differences in sexual assault victimization among college students. Violence Vict. 6, 922-940. doi: 10.1891/0886-6708.27.6.922

Ilabaca, P., Fuertes, A., and Orgaz, B. (2015). Impacto de la coerción sexual en la salud mental y actitud hacia la sexualidad: un estudio comparativo entre Bolivia, Chile y España [Impact of sexual coercion on mental health and attitude toward sexuality: a comparative study between Bolivia, Chile, and Spain]. Psykhe 24, 1-13. doi: 10.7764/psykhe.24.1.558

INJUV (2013). 7ma Encuesta Nacional de Juventud 2012 [7th National Youth Survey 2012]. Available online at: http://www.injuv.gob.cl/portal/wp-content/ files_mf/septimaencuestanacionaljuventud2.pdf

Kolivas, E. D., and Gross, A. M. (2007). Assessing sexual aggression: addressing the gap between rape victimization and perpetration prevalence rates. Aggress. Violent Behav. 12, 315-328. doi: 10.1016/j.avb.2006.10.002

Koss, M. P. (1993). Detecting the scope of rape: a review of prevalence research methods. J. Interpers. Violence 8, 198-222. doi: 10.1177/0886260930080 02004

Koss, M. P., Abbey, A., Campbell, R., Cook, S., Norris, J., Testa, M., et al. (2007). Revising the SES: a collaborative process to improve assessment of sexual aggression and victimization. Psychol. Women Q. 31, 357-370. doi: 10.1111/j.1471-6402.2007.00385.x

Koss, M. P., Abbey, A., Campbell, R., Norris, J., Testa, M., Ullman, S., et al. (2008). Erratum: scoring based on individual items. Psychol. Women Q. 32, 493-493. doi: 10.1111/j.1471-6402.2008.00468.x

Koss, M. P., Gidycz, C. A., and Wisniewski, N. (1987). The scope of rape: incidence and prevalence of sexual aggression and victimization in a national sample of higher education students. J. Consult. Clin. Psychol. 55, 162-170. doi: 10.1037/0022-006X.55.2.162

Krahé, B., and Berger, A. (2013). Men and women as perpetrators and victims of sexual aggression in heterosexual and same-sex encounters: a study of first-year college students in Germany. Aggress. Behav. 39, 391-404. doi: $10.1002 / \mathrm{ab} .21482$

Krahé, B., Berger, A., Vanwesenbeeck, I., Bianchi, G., Chliaoutakis, J., Fernández-Fuertes, A. A., et al. (2015). Prevalence and correlates of young people's sexual aggression perpetration and victimisation in 10 European countries: a multi-level analysis. Cult. Health Sex. 17, 682-699. doi: 10.1080/13691058.2014.989265

Krahé, B., de Haas, S., Vanwesenbeeck, I., Bianchi, G., Chliaoutakis, J., Fuertes, A., et al. (2016). Interpreting survey questions about sexual aggression in crosscultural research: a qualitative study with young adults from nine European countries. Sex. Cult. 20, 1-23. doi: 10.1007/s12119-015-9321-2

Krahé, B., Tomaszewska, P., Kuyper, L., and Vanwesenbeeck, I. (2014). Prevalence of sexual aggression among young people in Europe: a review of the evidence from 27 EU countries. Aggress. Violent Behav. 19, 545-558. doi: 10.1016/j.avb.2014.07.005

Krahé, B., and Vanwesenbeeck, I. (2016). Mapping an agenda for the study of youth sexual aggression in Europe: assessment, principles of good practice, and the multilevel analysis of risk factors. J. Sex. Aggress. 22, 161-176. doi: 10.1080/13552600.2015.1066885

Lehrer, E. L., Lehrer, V. L., and Krauss, R. (2009). Religion and Intimate Partner Violence in Chile: Macro- and Micro-Level Influences (IZA discussion papers, No. 4067). Available online at: http://ftp.iza.org/dp4067.pdf

Lehrer, J. A., Lehrer, E. L., and Koss, M. P. (2013a). Sexual and dating violence among adolescents and young adults in Chile: a review of findings from a survey of university students. Cult. Health Sex. 15, 1-14. doi: 10.1080/13691058.2012.737934

Lehrer, J. A., Lehrer, E. L., and Koss, M. P. (2013b). Unwanted sexual experiences in young men: evidence from a survey of university students in Chile. Arch. Sex. Behav. 42, 213-223. doi: 10.1007/s10508-012-0004-x

Macintyre, A. K.-J., Montero Vega, A. R., and Sagbakken, M. (2015). From disease to desire, pleasure to the pill: a qualitative study of adolescent learning about sexual health and sexuality in Chile. BMC Public Health 15:945. doi: 10.1186/s12889-015-2253-9

Maida, A. M., Vásquez, A., Herskovic, V., Calderón, J. L., Jacard, M., Pereira, A., et al. (2003). A report on student abuse during medical training. Med. Teach. 25, 497-501. doi: 10.1080/01421590310001606317
Martin, S. L., Macy, R. J., and Young, S. K. (2011). "Health and economic consequences of sexual violence," in Violence Against Women and Children, eds J. W. White, M. P. Koss, and A. E. Kazdin (Washington, DC: American Psychological Association), 173-195.

Mason-Jones, A. J., and Cabieses, B. (2015). Alcohol, binge drinking and associated mental health problems in young urban Chileans. PLoS ONE 10:e0121116. doi: 10.1371/journal.pone.0121116

Ministerio de Salud Subsecretaría de Salud Pública (2010). Ley Núm. 20.418. Fija Normas Sobre Información, Orientación y Prestaciones en Materia de Regulación de la Fertilidad [Law 20418: Set Standards for Information, Guidance, and Services Pertaining to Fertility Regulation]. Available online at: https://www.leychile.cl/Navegar?idNorma=1010482\&idVersion=2010-02-02

Morán Faúndes, J. M. (2013). Feminismo, Iglesia Católica y derechos sexuales y reproductivos en el Chile post-dictatorial [Feminism, Catholic Church, and sexual and reproductive rights in post-dictatorship Chile]. Rev. Estud. Fem. 21, 485-508. doi: 10.1590/S0104-026X2013000200004

Pedersen, W. (2014). Forbidden fruit? A longitudinal study of christianity, sex, and marriage. J. Sex Res. 51, 542-550. doi: 10.1080/00224499.2012.753983

Perilloux, C., Muñoz-Reyes, J. A., Turiegano, E., Kurzban, R., and Pita, M. (2015). Do (non-American) men overestimate women's sexual intentions? Evol. Psychol. Sci. 1, 150-154. doi: 10.1007/s40806-015-0017-5

Peter, J., and Valkenburg, P. M. (2016). Adolescents and pornography: a review of 20 years of research. J. Sex Res. 53, 509-531. doi: 10.1080/00224499.2016.1143441

Peterson, Z. D., Voller, E. K., Polusny, M. A., and Murdoch, M. (2011). Prevalence and consequences of adult sexual assault of men: review of empirical findings and state of the literature. Clin. Psychol. Rev. 31, 1-24. doi: 10.1016/j.cpr.2010.08.006

Reissing, E. D., Andruff, H. L., and Wentland, J. J. (2012). Looking back: the experience of first sexual intercourse and current sexual adjustment in young heterosexual adults. J. Sex Res. 49, 27-35. doi: 10.1080/00224499.2010. 538951

Rothman, E. F., Exner, D., and Baughman, A. (2011). The prevalence of sexual assault against people who identify as gay, lesbian or bisexual in the United States: a systematic review. Trauma Violence Abuse 12, 55-66. doi: $10.1177 / 1524838010390707$

Russell, B. L., and Oswald, D. L. (2001). Strategies and dispositional correlates of sexual coercion perpetrated by women: an exploratory investigation. Sex Roles 45, 103-115. doi: 10.1023/A:1013016502745

Russell, B. L., and Oswald, D. L. (2002). Sexual coercion and victimization of college men: the role of love styles. J. Interpers. Violence 17, 273-285. doi: 10.1177/0886260502017003003

Saldivia, C., and Vizcarra, B. (2012). Consumo de drogas y violencia en el noviazgo en estudiantes universitarios del sur de Chile [Drug abuse and dating violence in university students in southern Chile]. Ter. Psicol. 30, 43-49. doi: 10.4067/S0718-48082012000200004

Schuster, I., Krahé, B., and Toplu-Demirtaş, E. (2016). Prevalence of sexual aggression victimization and perpetration in a sample of female and male college students in Turkey. J. Sex Res. doi: 10.1080/00224499.2016.1207057. [Epub ahead of print].

Straus, M. A. (2009). The national context effect: an empirical test of the validity of cross-national research using unrepresentative samples. Cross Cult. Res. 43, 183-205. doi: 10.1177/1069397109335770

Struckman-Johnson, C. (1988). Forced sex on dates: it happens to men, too. J. Sex Res. 24, 234-241. doi: 10.1080/00224498809551418

Swartout, K. M., Swartout, A. G., Brennan, C. L., and White, J. W. (2015). Trajectories of male sexual aggression from adolescence through college: a latent class growth analysis. Aggress. Behav. 41, 467-477. doi: 10.1002/ab.21584

Tomaszewska, P., and Krahé, B. (2015). Sexual aggression victimization and perpetration among female and male university students in Poland. J. Interpers. Violence. doi: 10.1177/0886260515609583. [Epub ahead of print].

Turchik, J. A., Hebenstreit, C. L., and Judson, S. S. (2016). An examination of the gender inclusiveness of current theories of sexual violence in adulthood: recognizing male victims, female perpetrators, and same-sex violence. Trauma Violence Abuse 17, 133-148. doi: 10.1177/1524838014566721

Ullman, S. E., Karabatsos, G., and Koss, M. P. (1999). Alcohol and sexual aggression in a national sample of college men. J. Interpers. Violence 14, 603-625. doi: 10.1177/088626099014006003 
United Nations Development Programme (2015). Human Development Report 2015: Work for Human Development. Available online at: http://hdr.undp.org/en/2015-report

WHO (2013). Global and Regional Estimates of Violence Against Women: Prevalence and Health Effects of Intimate Partner Violence and Non-partner Sexual Violence. Available online at: http://www.who.int/reproductivehealth/ publications/violence/9789241564625/en/

Williams, C. M., Cook-Craig, P. G., Bush, H. M., Clear, E. R., Lewis, A. M., Garcia, L. S., et al. (2014). Victimization and perpetration of unwanted sexual activities among high school students: frequency and correlates. Violence Against Women 20, 1239-1257. doi: 10.1177/1077801214551575
Conflict of Interest Statement: The authors declare that the research was conducted in the absence of any commercial or financial relationships that could be construed as a potential conflict of interest.

Copyright (c) 2016 Schuster, Krahé, Ilabaca Baeza and Muñoz-Reyes. This is an open-access article distributed under the terms of the Creative Commons Attribution License (CC BY). The use, distribution or reproduction in other forums is permitted, provided the original author(s) or licensor are credited and that the original publication in this journal is cited, in accordance with accepted academic practice. No use, distribution or reproduction is permitted which does not comply with these terms. 